\title{
Experimental and finite element simulation study of capsule-free hot isostatic pressing of sintered gears
}

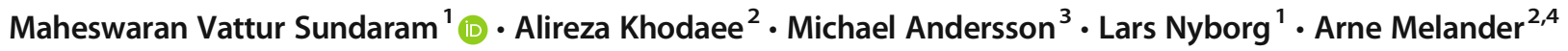

Received: 6 April 2018 / Accepted: 19 August 2018 / Published online: 25 August 2018

(C) The Author(s) 2018

\begin{abstract}
A novel approach to reach full density in powder metallurgy (PM) components is demonstrated in this work. Water-atomised Moprealloyed steel powder is utilised for manufacturing cylindrical and gear samples through double pressing and double sintering (DPDS) process route. The effect of sample geometry and powder size fraction on densification is investigated and it is found that the DPDS route enables a density level of $>95 \%$ which is sufficient to eliminate the surface open pores. Reaching such high density is necessary, in order to perform capsule-free hot isostatic pressing (HIP). After HIP, full densification is achieved for the cylindrical samples and only near full density is realised for the gears resulting in neutral zone formation due to the density gradient. In order to predict the densification behaviour during the compaction, FEM simulations considering the gear geometry are performed for both the pressing stages and HIP. The simulation predicted a similar densification behaviour with the formation of the neutral zone. The proposed DPDS route with capsule-free HIP in combination with FEM simulation is demonstrated as a potential route for manufacturing full-density PM steel components, e.g. gears, suitable for high-performance applications.
\end{abstract}

Keywords PM steels · Gears · Pressing $\cdot$ Capsule-free HIP · Density $\cdot$ Finite element simulations

\section{Introduction}

Gear manufacturing through powder metallurgy (PM) route has an inherent advantage to form components with complex shapes and profiles from a single pressing operation in large volumes, compared to conventional gear manufacturing, where the typical process involves machining and gear cutting from the blank [1]. Further, PM processing is an economical route as it generates less raw material wastage over the metal cutting process and is also energy efficient [2, 3]. However, PM steels, regardless of all its advantages, are limited by the presence of pores when it comes to high-performance applications especially in dynamic loading conditions [4-6].

Maheswaran Vattur Sundaram

vattur@chalmers.se

1 Department of Industrial and Materials Science, Chalmers University of Technology, SE-41296 Gothenburg, Sweden

2 Production Engineering Department, KTH Royal Institute of Technology, SE-10044 Stockholm, Sweden

3 Höganäs AB, SE-26383 Höganäs, Sweden

4 Swerea KIMAB, SE-16407 Stockholm, Sweden
Therefore, there is a need for continuous process improvement, in order to increase the density of PM steel component. The mechanical property of the PM steel component is dependent primarily on the density levels; higher the density better will be the mechanical properties [7]. When it comes to gears for heavy-duty and automotive transmissions, fatigue properties play a vital role and density has a significant effect on the final performance of the gear since it has a direct relation to the mechanical properties. Porosity plays a significant influence on the properties of PM steel [8] and the pore size, pore structure and its distribution within the sample are known to affect the fatigue properties [9-11] by initiating the crack.

Post processing operations, such as surface rolling, will increase the load-bearing capacity of the PM gears, resulting in surface densification and thus improving the fatigue properties $[12,13]$. Another approach is to increase the density levels of PM components to around 95\%, which in turn enables to reach full density after performing capsule-free hot isostatic pressing (HIP) [14-16]. In order to perform capsulefree HIP, it is necessary to have the surface open pores closed; otherwise, any presence of surface open pores which are interconnected will not be densified after capsule-free HIP $[17,18]$ whereas closed pores are successfully HIP:ed to reach full density $[19,20]$. When it comes to water-atomised 
low-alloyed steel powder, it has been shown that the transition from open to closed porosity occurs around $95 \%$ of the density levels after sintering at high temperatures [21] which enables the surface pore closure [16]. Also, reaching such high density is necessary for PM steel components to retain the dimensional stability after HIP. The main advantage of this process is that the HIP capsules are eliminated and in addition to that, with the recent technological advancements in HIP, it is possible to combine the operations, such as heat treatment and quenching, which further reduces the overall processing cost $[20,22]$.

In this study, an approach for manufacturing fully dense PM steel, utilising Mo-prealloyed water-atomised powder was proposed. The effect of powder particle size and part geometry (cylinders and gears) upon pressing, sintering and HIP on densification was analysed. Techniques such as Hepycnometry and image analysis were used for pore analysis. In order to further develop and optimise the process route, an analytical model using the finite element method (FEM) was established based on the experimental results.

\section{Materials and methods}

\subsection{Experimental}

Water-atomised steel powder prealloyed with $1.5 \mathrm{wt} \%$ Mo (Astaloy Mo) produced by Höganäs AB, Sweden [23], was used in standard $(20$ to $180 \mu \mathrm{m})$ and fine $(<63 \mu \mathrm{m})$ powder size fractions admixed with $0.6 \mathrm{wt} \%$ LubeE lubricant and $0.2 \mathrm{wt} \%$ UF4 natural graphite as a carbon source. Cylindrical samples $(\varnothing 25 \mathrm{~mm} \times 20 \mathrm{~mm})$ and gear specimens $(\mathrm{mn}=1.5875, Z=18, b=10 \mathrm{~mm}$ and $d=31.75 \mathrm{~mm})$ were compacted and used for investigations as given in Table 1 . Figure 1 displays the process flow adopted in this study, where two pressing and sintering stages were considered followed by the HIP. The process begins with the initial compaction stage, first pressing (1P) at $800 \mathrm{MPa}$ and then presintering (1S) at $800{ }^{\circ} \mathrm{C}$ in $\mathrm{N}_{2}$ atmosphere to remove the lubricants and to anneal the material for the next stage of compaction, then repressed (2P) at $800 \mathrm{MPa}$ and sintered (2S) at $1300{ }^{\circ} \mathrm{C}$ for $1 \mathrm{~h}$ in vacuum in an industrial furnace. Then, the samples were hot isostatically pressed without capsules at $1150{ }^{\circ} \mathrm{C}$ for $2 \mathrm{~h}$ using argon gas pressure of $100 \mathrm{MPa}$ in QIH21 HIP at Quintus Technologies AB. The selected process parameters are optimum based on the previous studies $[14,15]$.

The density was measured according to ISO 3369 for sintered samples using Archimedes' method. The metallographic samples were prepared after $1 \mathrm{~S}, 2 \mathrm{~S}$ and HIP to investigate the pressing and sintering effect on densification. The optical images were obtained using a Leica DMRX optical microscope and SEM images were obtained using an FEGSEM LEO 1550 Gemini scanning electron microscope.
Table 1 Overview of process variants using Astaloy Mo +0.2 wt\% $\mathrm{C}+0.6 \mathrm{wt} \%$ lubricants

\begin{tabular}{lll}
\hline Samples & Powders & Designation \\
\hline Cylinders & Standard $(20$ to $180 \mu \mathrm{m})$ & Cylinder B \\
& Fine $(<63 \mu \mathrm{m})$ & Cylinder C \\
Gears & Standard $(20$ to $180 \mu \mathrm{m})$ & Gear B \\
& Fine $(<63 \mu \mathrm{m})$ & Gear C \\
\hline
\end{tabular}

Porosity analysis was performed on 10 images taken at $\times 200$ magnification using the ImageJ software. The theoretical density of this is material is $7.89 \mathrm{~g} / \mathrm{cm}^{3}$ and it is used to calculate the total porosity after measuring the density from the Archimedes method. To determine the amount of open and closed porosity, He-pycnometer measurements were performed [24] using an AccuPycII $1340 \mathrm{He}$-pycnometer. It provides the pycnometer density, from this value the closed porosity is estimated and by subtracting it from the total porosity, the amount of open porosity is obtained.

\subsection{FEM process simulations}

In order to formulate the material response under the two pressing stages and HIP, a selection of suitable material model is necessary for the FEM simulations to describe the development of the local density distribution.

\subsubsection{Material model}

Two groups of constitutive models are developed in order to simulate the powder behaviour during powder pressing and HIP. The first group includes models based on porous material densification mechanism, appropriate for high-density PM components.

Classical Von Mises model is used to develop a porous model by adding the modifications to consider the influence of porosities in the material structure which will take into account the effects of hydrostatic pressure on the yield criterion. The second group of constitutive models are adopted from soil mechanics and are used for simulation of initial metal powder pressing when there are no bonds between powder particles [25].

In this work, 1P simulation is performed using the "modified Drucker-Prager" or "CAP" model which is a well-known granular model. The overall dimensions and density distribution of the components during pressing were captured using

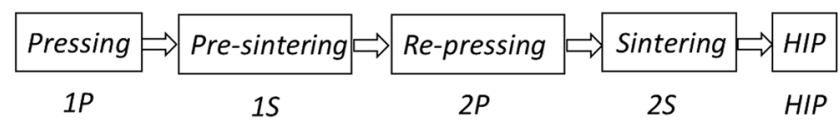

Fig. 1 PM process flow used in this study 

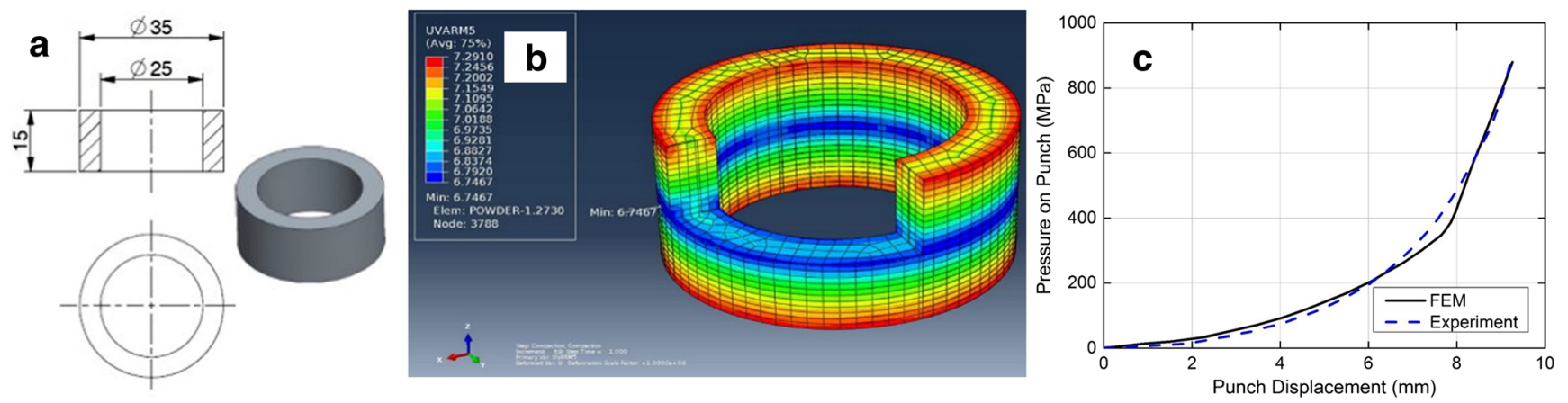

Fig. 2 Specimen drawing for the experimental compaction tests (a), simulation of the compaction test result (b), and the fitted curve for the experimental material response with optimised CAP parameters (c)

Table 2 Modified Drucker-Prager model CAP plasticity parameters in ABAQUS for the simulation of $1 \mathrm{P}$

\begin{tabular}{llllll}
\hline $\begin{array}{l}\text { Material } \\
\text { cohesion } \\
{[\mathrm{MPa}]}\end{array}$ & $\begin{array}{l}\text { Angle } \\
\text { of } \\
\text { friction } \\
{\left[{ }^{\circ}\right]}\end{array}$ & $\begin{array}{l}\text { Cap } \\
{[-]}\end{array}$ & $\begin{array}{l}\text { Initial yield } \\
\text { surface } \\
\text { position } \\
{[\mathrm{MPa}]}\end{array}$ & $\begin{array}{l}\text { Transition } \\
\text { surface } \\
\text { radius }[-]\end{array}$ & $\begin{array}{l}\text { Flow } \\
\text { stress } \\
\text { ratio } \\
{[-]}\end{array}$ \\
\hline 0.059 & 70.55 & 0.5 & 0.01 & 0.01 & 1 \\
\hline
\end{tabular}

this model [26]. According to Hrari et al., this model has shown acceptable accuracy in predicting the results during cold die pressing [25]. Whereas to describe the component behaviour for 2P and HIP simulations, the "Gurson" model is used [27]. It is integrated into ABAQUS as a continuum model and is able to predict the global density and overall dimensional changes of the porous metals with high accuracy. However, both the sintering processes $1 \mathrm{~S}$ and $2 \mathrm{~S}$ are not modelled by FEM simulation, and the sintering effect after $1 \mathrm{~S}$ on the relative density $(\mathrm{RD})$ distribution is considered with a linear modification factor. For this purpose, the resulted density distribution after $1 \mathrm{P}$ is modified by applying a modification factor on the relative densities of the mesh nodes from the $1 \mathrm{P}$ output file and then used as the input RD file for $2 \mathrm{P}$ simulation. The same method is used to modify the results of $\mathrm{RD}$ distribution after $2 \mathrm{P}$ and using it as the input $\mathrm{RD}$ file for HIP simulation.

\subsubsection{Model parameters}

The 1P, $2 \mathrm{P}$ and HIP parameters, together with the sintering modification factors for $1 \mathrm{~S}$ and $2 \mathrm{~S}$, are given in this section. In order to define CAP parameters, an initial estimate based on the previous work is made $[28,29]$.

The ring compaction tests were performed on the specimen as shown in Fig. 2a using the standard powder size fraction. Then, the compaction test in FEM simulation is performed using the CAP model as in Fig. $2 b$ and it is optimised to reach an accurate fit between the FEM and experimental results as shown in Fig. 2c. Based on this procedure, CAP parameters for PM gear simulation is obtained as given in Table 2, whereas for $2 \mathrm{P}$ and HIP simulations, all the pores are assumed to be spherical in shape. Hence, all of the three parameters of the Gurson model (q1, q2 and q3) will be equal to 1 and that is used in the FEM simulations $[30,31]$. To consider the sintering effects, the modification factor of relative density equal to $-0.69 \%$ and $-0.50 \%$ for $1 \mathrm{~S}$ and $2 \mathrm{~S}$ respectively is applied to the FE model results of
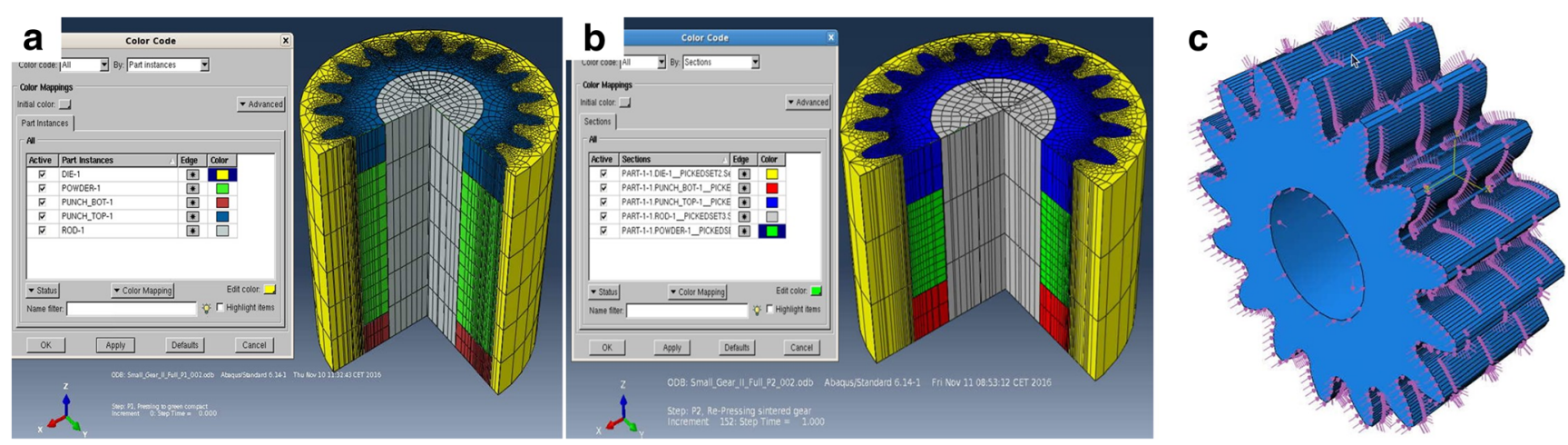

Fig. 3 3D geometrical model simulation from ABAQUS for first pressing (a), second pressing (b) and HIP simulation with isostatic pressure applied all over all the gear $(\mathbf{c})$ 
Fig. 4 Density levels at different process stage measured by Archimedes' method for the cylindrical (a) and gear (b) specimens

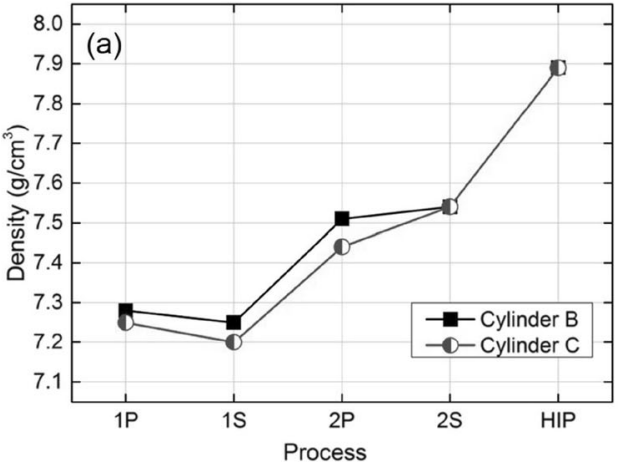

$1 \mathrm{P}$ and $2 \mathrm{P}$ simulations. This modification factor is defined by the results of experiments and density measurements before and after $1 \mathrm{~S}$ and $2 \mathrm{~S}$.

\subsubsection{Mesh setup, boundary conditions and friction effects}

The geometrical model of the $1 \mathrm{P}, 2 \mathrm{P}$ and HIP process are presented in Fig. 3a-c.

The FEM simulations are performed using ABAQUS Standard, with the mesh density of 1 element per $1 \mathrm{~mm}$ in the radial direction and $2 \mathrm{~mm}$ in the face-width direction.
To mesh the PM component, 8 node linear brick elements (C3D8R) were used.

In order to simplify the model, and also to reduce the calculation time and cost, all the dies and punches were considered to be rigid in these simulations. The $1 \mathrm{P}$ and $2 \mathrm{P}$ are modelled with displacement control for the two punches. Top punch and bottom punch are pressing the gear while the outer die and central rod are fixed in space and the PM gear is able to be compacted and densified due to pressure generated from punch movements. For HIP simulation, the PM gear freedom of rotation is fixed in and the isostatic pressure applied to all the gear surfaces. A friction factor of 0.2 was defined for all the contacting
15
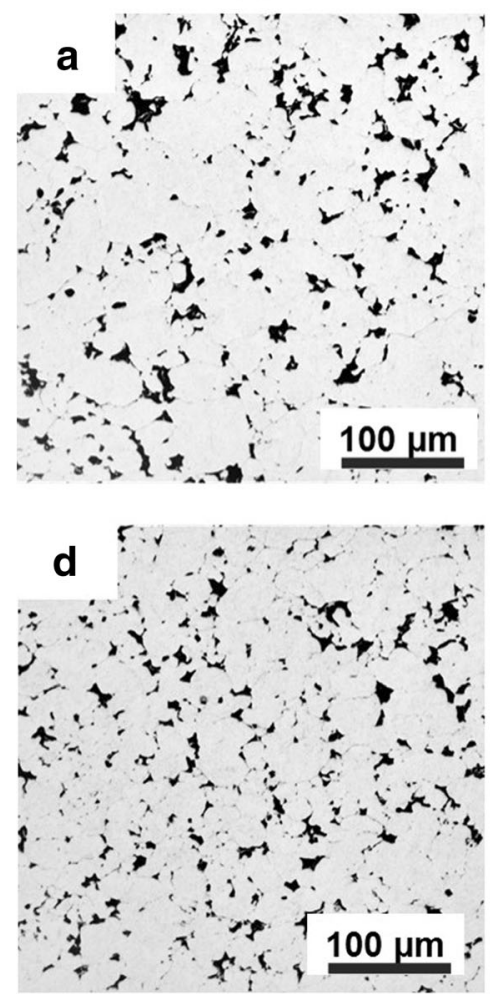

$2 S$
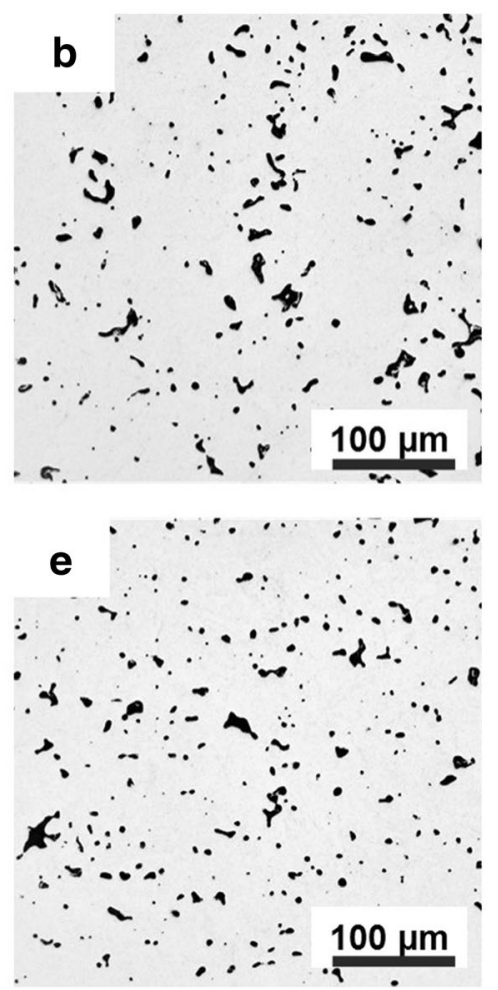

HIP

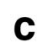

$100 \mu \mathrm{m}$

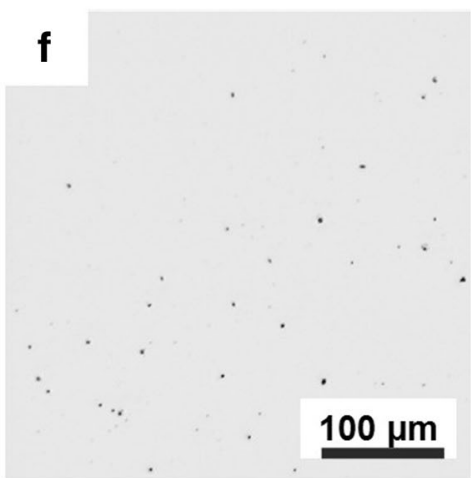

Fig. 5 Polished micrographs of the gear samples after 1S, 2S and HIP. Gear B (a-c) and Gear C (d-f) 
Table 3 Density and total porosity of the bulk samples from Archimedes' open and closed porosity from He-pycnometer measurements and total porosity from image analysis after $1 \mathrm{~S}, 2 \mathrm{~S}$ and HIP process stage

\begin{tabular}{|c|c|c|c|c|c|c|}
\hline \multirow[t]{2}{*}{ Specimens } & \multirow[t]{2}{*}{ Process } & \multirow[t]{2}{*}{ Density $\mathrm{g} / \mathrm{cm}^{3}$} & \multicolumn{3}{|c|}{ Porosity $\%$} & \multirow[t]{2}{*}{ Total porosity $\%$} \\
\hline & & & Total & Open & Closed & \\
\hline \multirow[t]{3}{*}{ Cylinder B } & $1 \mathrm{~S}$ & 7.26 & 8.0 & 7.2 & 0.7 & $8.2 \pm 0.6$ \\
\hline & $2 \mathrm{~S}$ & 7.55 & 4.4 & - & 4.4 & $4.7 \pm 0.5$ \\
\hline & HIP & 7.89 & 0.2 & - & 0.2 & - \\
\hline \multirow[t]{3}{*}{ Cylinder C } & $1 \mathrm{~S}$ & 7.22 & 8.5 & 8.0 & 0.5 & $8.4 \pm 0.7$ \\
\hline & $2 \mathrm{~S}$ & 7.55 & 4.6 & - & 4.6 & $4.9 \pm 0.3$ \\
\hline & HIP & 7.89 & 0.1 & - & 0.1 & - \\
\hline \multirow[t]{3}{*}{ Gear B } & $1 \mathrm{~S}$ & 7.22 & 8.5 & 7.5 & 1.0 & $8.3 \pm 1.0$ \\
\hline & $2 \mathrm{~S}$ & 7.49 & 5.1 & 0.8 & 4.3 & $5.2 \pm 0.6$ \\
\hline & HIP & 7.85 & 0.6 & - & 0.6 & - \\
\hline \multirow[t]{3}{*}{ Gear C } & $1 \mathrm{~S}$ & 7.16 & 9.3 & 8.8 & 0.5 & $8.8 \pm 0.7$ \\
\hline & $2 \mathrm{~S}$ & 7.52 & 4.7 & - & 4.7 & $5.8 \pm 0.4$ \\
\hline & HIP & 7.87 & 0.5 & - & 0.5 & - \\
\hline
\end{tabular}

surfaces in the simulation models of $1 \mathrm{P}$ and $2 \mathrm{P}$ to consider the effects of friction during the process by using Coulomb friction.

\section{Results and discussions}

\subsection{Effect of DPDS and HIP process on densification}

The densification behaviour of the samples during double pressing and double sintering and HIP is presented and discussed in this section. The density of cylindrical and gear specimens after pressing, sintering and HIP is given in Fig. 4a, b. The major densification is from the two pressing stages and the density reached after $1 \mathrm{P}$ is around $\sim 7.25$ to $7.3 \mathrm{~g} / \mathrm{cm}^{3}$ at $800 \mathrm{MPa}$. The maximum density that can be achieved without any delamination or cracks during pressing is $98 \%$ of the porefree density (PFD) $[32,33]$, which is around $7.4 \mathrm{~g} / \mathrm{cm}^{3}$ in this case with $0.2 \mathrm{wt} \%$ graphite and $0.6 \mathrm{wt} \%$ lubricant. Also, the standard powder samples (Cylinder B and Gear B) display a better densification after $1 \mathrm{P}$ as compared to the fine powder specimens. The effect of part geometry on the densification is evident from the increase in density after 1P for the cylindrical specimens.

The first sintering process (1S) at $800{ }^{\circ} \mathrm{C}$ is mainly to remove the admixed lubricants and to anneal the compact for subsequent pressing. For both the cylinder and gear samples, $1 \mathrm{~S}$ results in a minor drop in the density levels due to lubricant removal as observed in Fig. 4a, b. For the standard powder specimens (Cylinder B and Gear B), the decrease in density is $\sim 0.4 \%$ and $0.5 \%$ and for the fine powder specimens (Cylinder $\mathrm{C}$ and Gear $\mathrm{C}$ ), the decrease in density is $\sim 0.7 \%$ and $0.8 \%$. The optical micrographs in Fig. 5a, d show the typical pore structure after the $1 \mathrm{~S}$ stage and Table 3 summarises the results from $\mathrm{He}$-pycnometer measurements and image analysis.
The results obtained show more open pores for gear specimens when compared to the cylinders. This is connected to the geometrical effect arising from the gear, generating high frictional forces from the high surface area in contact with the die during pressing resulting in the density gradient. Furthermore, the fine powder samples (Cylinder C and Gear C) exhibit a larger fraction of open pores than that of the standard powder samples (Cylinder B and Gear B), due to the powder-packing characteristic of standard and fine powder. Even though the fine powder specimens exhibit a larger amount of total porosity, the average pore size is observed to be smaller than the standard specimens [15] and this can be noted from Fig. 5a, d. The lower fraction of closed porosity after $1 \mathrm{~S}$ indicates the presence of open porosity as a continuous network of interconnected pores which assists in an effective removal of the lubricants and resulting in more voids for

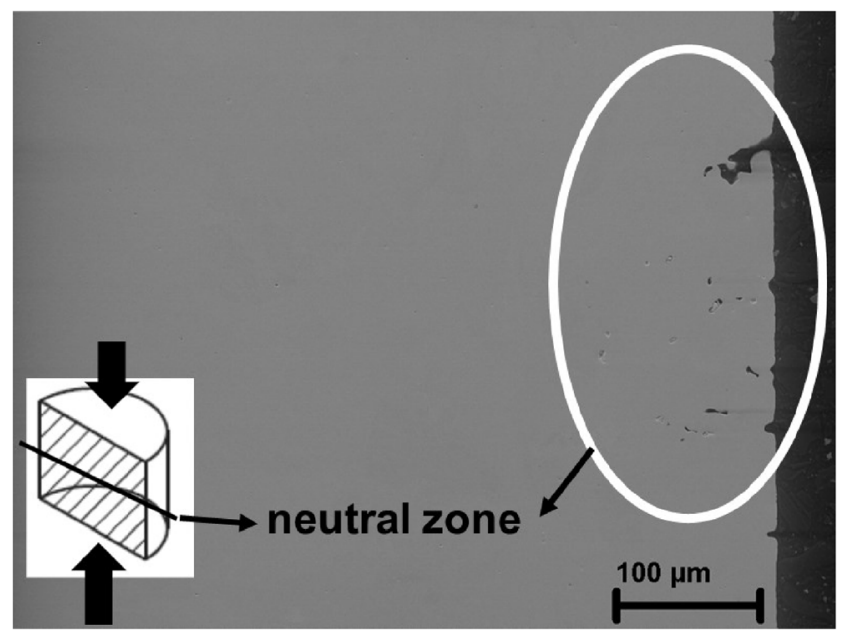

Fig. 6 SEM micrograph of the polished cross section from Cylinder C after HIP 
Table 4 Porosity from image analysis at the neutral zone cross section from the tooth and centre of the gear specimens

\begin{tabular}{|c|c|c|c|c|c|c|}
\hline \multirow[t]{3}{*}{ Specimens } & \multicolumn{6}{|c|}{ Porosity $\%$, in the neutral zone } \\
\hline & \multicolumn{2}{|l|}{$1 \mathrm{~S}$} & \multicolumn{2}{|l|}{$2 \mathrm{~S}$} & \multicolumn{2}{|l|}{ HIP } \\
\hline & Tooth & Centre & Tooth & Centre & Tooth & Centre \\
\hline Gear B & $12.1 \pm 1.8$ & $8.4 \pm 1.0$ & $5.3 \pm 0.6$ & $4.0 \pm 0.2$ & $6.8 \pm 1.0$ & - \\
\hline Gear C & $12.7 \pm 1.9$ & $8.2 \pm 1.1$ & $6.2 \pm 0.7$ & $4.2 \pm 0.3$ & - & - \\
\hline
\end{tabular}

further densification. Second pressing (2P) results in a drastic increase in density after $1 \mathrm{~S}$ by closing the pores left from the lubricant removal. The densification trend follows the previous process steps and prior effect still persists.

A final sintering is necessary to impart the strength through bond formation by generating inter-particle necks. Sintering at a temperature of $1300^{\circ} \mathrm{C}$ is necessary in order to transform all the open pores to closed pores [15]. Second sintering $(2 \mathrm{~S})$ at $1300{ }^{\circ} \mathrm{C}$ for $1 \mathrm{~h}$ revealed a small increase in density for standard samples, but it is prominent for fine fraction samples (Cylinder $\mathrm{C}$ and Gear $\mathrm{C}$ ), with an increase in density up to $1.5 \%$. However, the standard powdered samples (Cylinder B and Gear B) displayed an increase in density only up to $0.5 \%$, whereas the fine powder samples (Cylinder $\mathrm{C}$ and Gear C) displayed a better sintering effect resulting in a better densification than the standard powder samples, see Fig. 4. Optical micrograph from Fig. 5b, e displays the typical pore morphology after high temperature sintering, and from Hepycnometer results (Table 3 ), it is evident that all the open pores are transformed to closed pores after $2 \mathrm{~S}$ for Cylinder B, C and Gear C, except Gear B which retains small amount of open pores. It has been shown earlier [15], for the samples with fine powders, the resulting average pore size is finer, which makes it easier to close the pores after $2 \mathrm{~S}$ and that enables capsule-free HIP to reach full densification, as seen in Table 3.

Finally, HIP without any capsule results in almost full densification, see Fig. 5c, f. The important requirement to do capsule-free HIP is $95 \%$ relative density or above in order to have a surface closure of pores to enable full densification
[16]. Results from Table 3 indicate almost full density after HIP, except for the gear sample which is left with $\sim 0.5$ to $1 \%$ residual closed porosity. HIP:ing will not eliminate the pores if they are connected to the surface $[17,18]$ as indicated in Fig. 6.

The middle section of the sample experiences a density gradient during die pressing as the pressure effect is minimum resulting in a low density region called the neutral zone [15]. This region with lower density at the middle will have open pores which are not possible to be closed after capsule-free HIP. Meanwhile, the neutral zone arises after first pressing and dominant in the gear specimen $[15,29]$. In order to map the regions where the presence of pores is evident in the samples, the samples were sectioned exactly at the neutral zone and prepared for analysing the porosity.

The amount of porosity within the gear tooth and centre region from image analysis after $1 \mathrm{~S}, 2 \mathrm{~S}$ and HIP process stage is given in Table 4. As observed, there is a clear difference in porosity levels between the two regions for all the samples and the tooth region shows a higher amount of porosity reaching density levels of $\sim 6.9 \mathrm{~g} / \mathrm{cm}^{3}$ after $1 \mathrm{~S}$ for Gear $\mathrm{B}$ and Gear $\mathrm{C}$ samples. After $2 \mathrm{~S}$, the porosity level decreases, reaching density levels up to $\sim 7.5 \mathrm{~g} / \mathrm{cm}^{3}$ in the centre and at the tooth, it varies from $\sim 7.4$ to $7.47 \mathrm{~g} / \mathrm{cm}^{3}$ for Gears B and C. Figure 6 shows the SEM micrograph of Cylinder C sample along the axis at the neutral zone after HIP, where only small pore openings are visible, but for the gear samples after HIP, the presence of porosity is evident inside the gear tooth, as indicated in Fig. 7. The cross section of Gears B and C after HIP from Fig. 7b, c shows the presence of pores in the
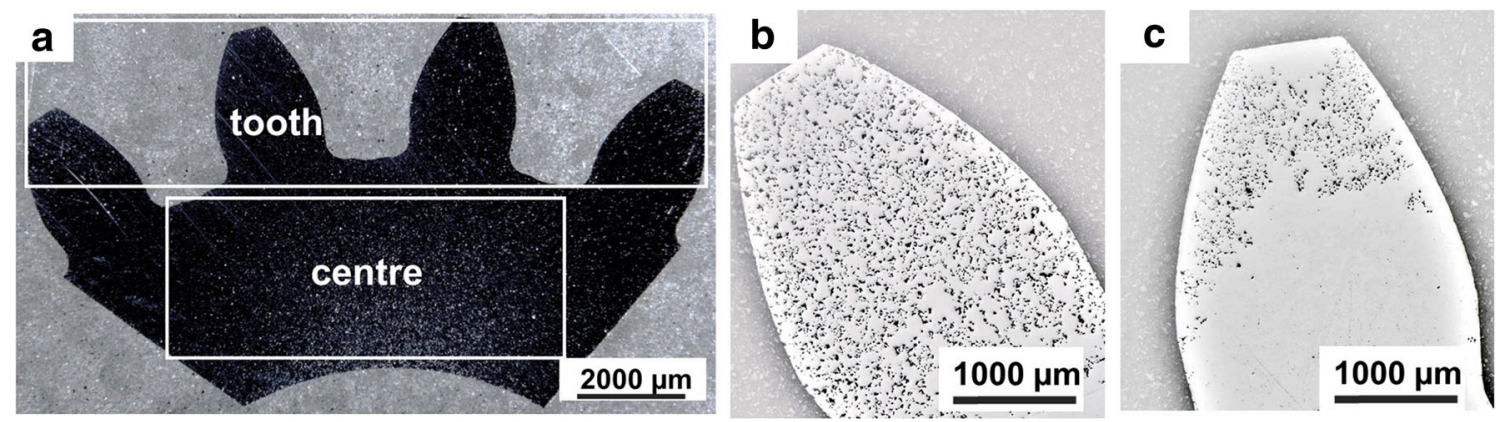

Fig. 7 Micrographs of the gear cross section showing the analysed tooth and the centre region for the gear samples (a), tooth region of the samples after HIP sectioned at the neutral zone, Gear B (b) and Gear C (c) 
a First pressing (1P)

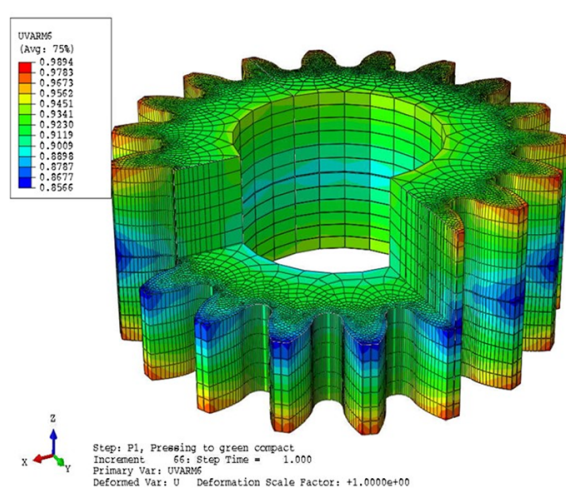

b

Second pressing (2P)

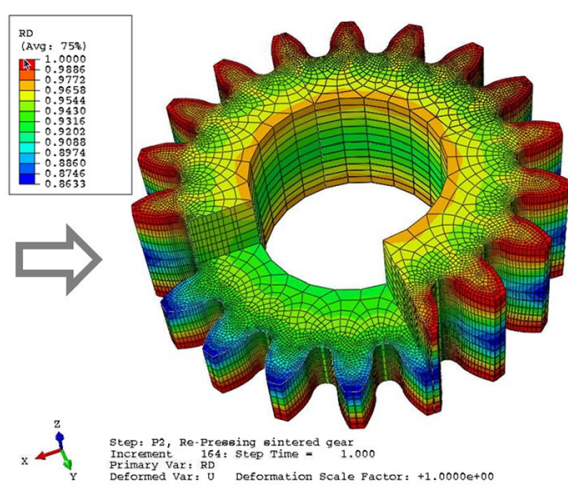

C Hot isostatic Pressing (HIP)

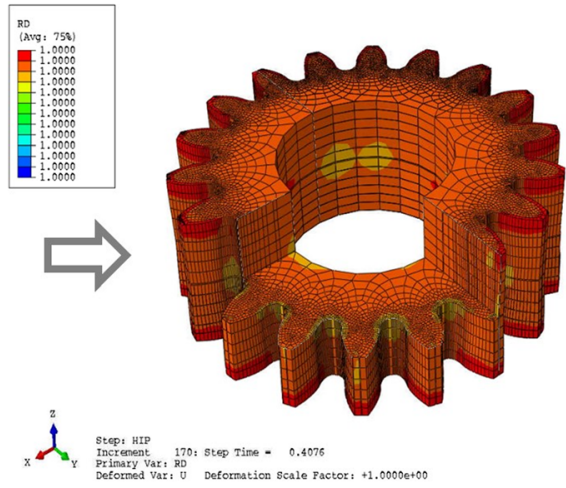

Fig. 8 Results from FEM simulation of the gears at different processing stages. First pressing (a), second pressing (b) and HIP (c)

neutral zone where Gear $\mathrm{C}$ is less porous than Gear B. The effect of pressing (1P) on the initial density affects the final densification after HIP by not reaching to full density, especially for gears.

\subsection{FEM simulations}

The resulted density distribution from FE simulation after 1P, $2 \mathrm{P}$ and HIP stages is shown in Fig. 8 and the average density is calculated based on the nodal values. An average density of $7.24 \mathrm{~g} / \mathrm{cm}^{3}$ after $1 \mathrm{P}$ is predicted from FEM which is around $91.8 \%$ of the relative density. The resulted density distribution in the component is illustrated in Fig. $8 \mathrm{~b}$ for $2 \mathrm{P}$ and is predicted to be $7.5 \mathrm{~g} / \mathrm{cm}^{3}$ which is around $95.1 \%$ of the relative density. Finally, the output from $2 \mathrm{P}$ was used as an input for the HIP FE simulation, using a similar approach for average density from past two simulations. As indicated in Fig. 9, the dimensions were measured in those gear regions and the average density of the component is predicted to be $7.89 \mathrm{~g} / \mathrm{cm}^{3}$, see Fig. 10a.
The FE model, shown in Fig. 8, illustrates the neutral zone generation in the middle section of the gear having a lower density even after 2P. This neutral zone will cause geometrical distortions afterwards during HIP due to the highdensity gradients close to that area of the gear. In order to develop a method for manufacturing gears with high precision, it would be necessary to predict maximum distortions occurring beneath this area, and then compensate for those in the process of die design; however, it is not the scope of this present study.

Figure 10a is showing the average density in the component after each process step from the simulations and experiments. The results show that the used simulation model is precise in predicting the material response during the process and necessary for further development of the process route. Khodaee et al. [29] have shown, by using the same material model and modifying the gear geometry, the density gradient can be eliminated by having lower gear width and higher gear module. The formation of neutral zone is predicted well by the FE simulations for the geometry studied in this work. The FE model also predicts the distortions that occur in each process
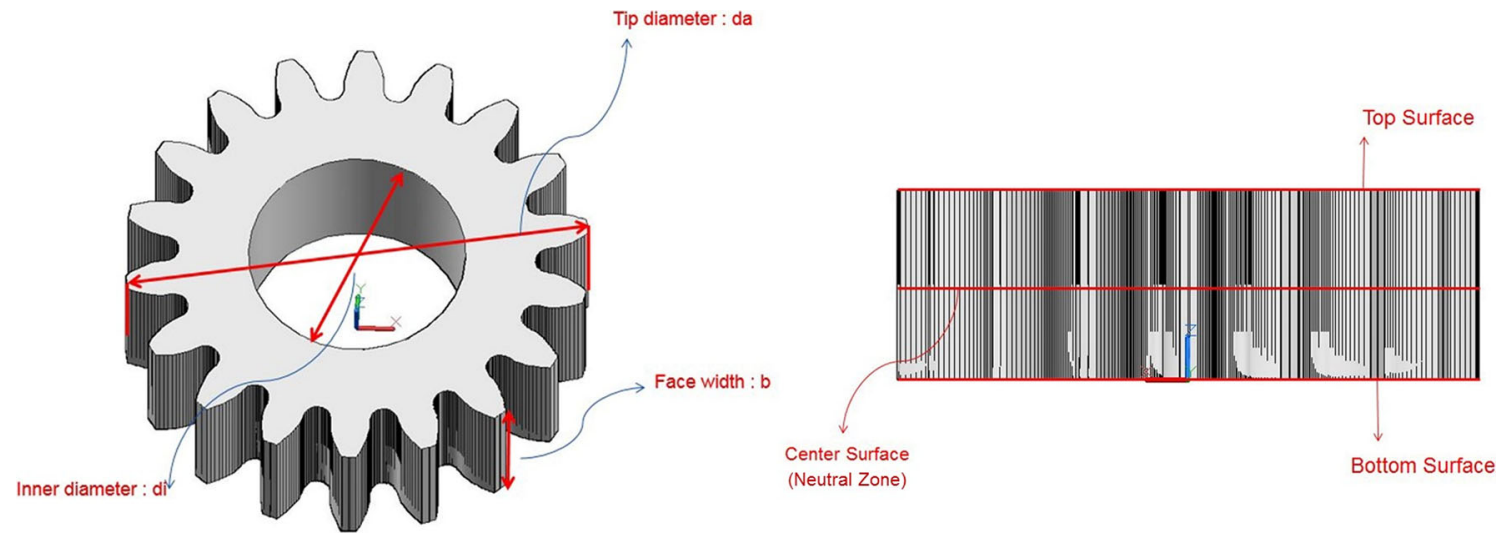

Fig. 9 Gear illustration showing the parameters measured from the different regions for the actual and FEM measurements 
Fig. 10 Comparison between actual measurements and results from FEM simulation at different stages. Average density (a), tip diameter (b), inner diameter (c) and face width (d)
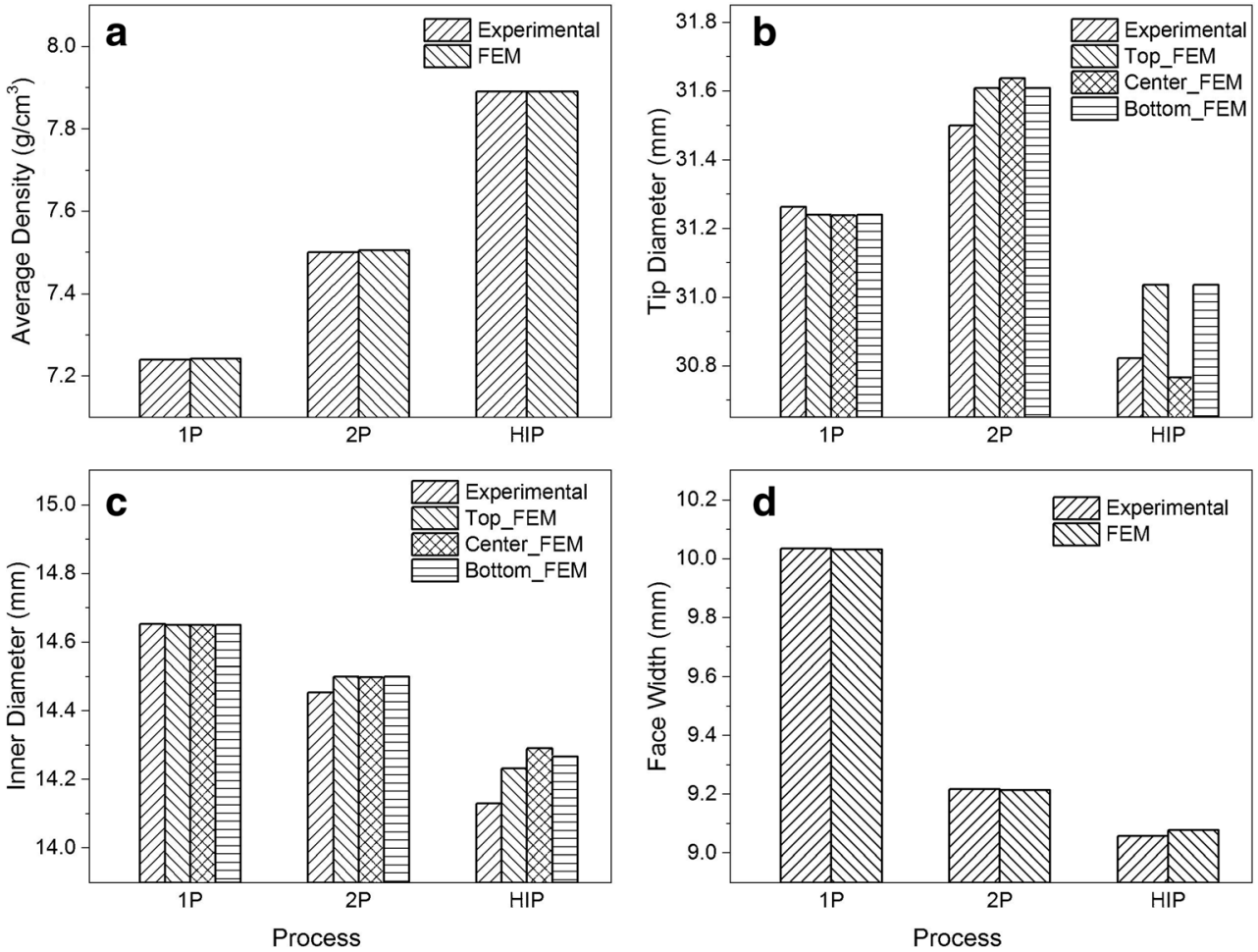

stage by simulating the density distribution along the neutral zone, see Fig. 10b-d and HIP results in more deviations.

An FE model for 1P, 2P and HIP was developed based on valid experiments from this study. The proposed simulation model can help to optimise the tool design for compaction in a way that distortions can be compensated in the process prior to HIP and by optimising the die geometry, the pressure effects in the HIP stage can be predicted. The validated model can be used for process development as a numerical approach with economical and time-efficient experiments by testing the process for new geometries.

\section{Conclusions}

The double pressing and double sintering process route with capsule-free HIP was utilised in this study, for manufacturing PM steel components especially aiming at the full-density gears. In order to simulate the experimental conditions and to further optimise the process parameters, FEM modelling considering CAP and Gurson material models for the compaction were used. The results indicated that full-density PM steel components can be reached through capsule-free HIP. The DPDS process enables PM steel components to reach $\sim 95 \%$ of density levels for surface pore closure that assists in full densification during capsule-free HIP. Sintering at a high temperature of $1300{ }^{\circ} \mathrm{C}$ for $1 \mathrm{~h}$ is necessary for surface pore closure and the fine powder shows better densification after sintering. The geometry of the component has an effect on densification during pressing, as observed from the densities of cylindrical samples compared to the gears. Neutral zone problem arises from the initial compaction process especially for the gear samples due to the geometrical effect. The implemented FE simulation model indicated a good agreement with the experimental results by predicting the formation of the neutral zone during the initial compaction stage. Also, the simulation helps in predicting the distortions that arise in each process as a result of the existing density gradients. FE simulation is a vital tool in designing the processing route for manufacturing PM gears which is time and cost efficient for developing an optimised gear geometry.

Acknowledgements The authors would like to acknowledge Vinnova (Swedish agency for innovation systems) for funding the HIP Gear project (Dnr: 2013-05594) within the framework of the FFI programme. Magnus Ahlfors from Quintus Technologies AB is acknowledged for supporting with the HIP trails.

Open Access This article is distributed under the terms of the Creative Commons Attribution 4.0 International License (http:// creativecommons.org/licenses/by/4.0/), which permits unrestricted use, distribution, and reproduction in any medium, provided you give appropriate credit to the original author(s) and the source, provide a link to the Creative Commons license, and indicate if changes were made.

Publisher's Note Springer Nature remains neutral with regard to jurisdictional claims in published maps and institutional affiliations. 


\section{References}

1. Krokha VA, Bakhovkin AM (1964) An advanced method for the manufacture of gears. Sov Powder Metall Met Ceram 2:81-85. https://doi.org/10.1007/BF00774142

2. Mascarenhas J (2004) Powder metallurgy: a major partner of the sustainable development. Mater Sci Forum 455:857-860

3. Dale JR (2011) Powder metallurgy-intrinsically sustainable. Int J Powder Metall (Princeton, New Jersey) 47:27-31

4. Hadrboletz A, Weiss B (1997) Fatigue behaviour of iron based sintered material: a review. Int Mater Rev 42:1-44. https://doi.org/ 10.1179/imr.1997.42.1.1

5. Danninger H, Spoljaric D, Weiss B, Stickler R (1998) High cycle fatigue behaviour of Mo alloyed sintered steel. Z Met Res Adv Tech 89:135-141

6. Zhang L, Liu Z, Sun H, Qin M, Qu X, Lyu Y (2017) Dynamic properties of high-density low-alloy PM steels. Powder Metall 60: 56-65. https://doi.org/10.1080/00325899.2016.1274815

7. Beiss P (2003) Iron and steel: manufacturing route, chap 5, structural mass production. Landolt-börnstein - gr. VIII Adv. Mater Technol:5-20

8. Beiss P, Dalgic M (2001) Structure property relationships in porous sintered steels. Mater Chem Phys 67:37-42. https://doi.org/10. 1016/S0254-0584(00)00417-X

9. Andersson M, Larsson M (2010) Linking pore size and structure to the fatigue performance of sintered steels. PM2010 World Congr. Fatigue Sintered Steels

10. Andersson M (2011) The role of porosity in fatigue of PM materials. Powder Metall Prog 11:21-31

11. Cipolloni G, Menapace C, Cristofolini I, Molinari A (2014) A quantitative characterisation of porosity in a $\mathrm{Cr}-\mathrm{Mo}$ sintered steel using image analysis. Mater Charact 94:58-68. https://doi.org/10. 1016/j.matchar.2014.05.005

12. Engström U, Fordén L, Bengtsson S, Bergström M (2006) Surface densification and warm compaction lead to greater density in PM gears, resulting in higher strength and improved fatigue properties. Gear Solut $18-22$

13. Dizdar S (2012) High-performance sintered-steel gears for transmissions and machinery : a critical review. Gear Technol 60-65

14. Flodin A, Andersson M, Miedzinski A (2016) Full density powder metal components through hot isostatic pressing. Met Powder Rep 72:2-5. https://doi.org/10.1016/j.mprp.2016.02.057

15. Strondl A, Khodaee A, Vattur Sundaram M, et al (2016) Innovative powder based manufacturing of high performance gears. World PM 2016 Congr. Exhib

16. Vattur Sundaram M (2017) Processing methods for reaching full density powder metallurgical materials. Chalmers University of Technology

17. Essa K, Jamshidi P, Zou J, Attallah MM, Hassanin H (2017) Porosity control in 316L stainless steel using cold and hot isostatic pressing. Mater Des 138:21-29. https://doi.org/10.1016/j.matdes. 2017.10.025
18. Hassanin H, Al-Kinani AA, ElShaer A et al (2017) Stainless steel with tailored porosity using canister-free hot isostatic pressing for improved osseointegration implants. J Mater Chem B 5:93849394. https://doi.org/10.1039/C7TB02444D

19. Magnusson H, Frisk K, Vattur Sundaram M, et al (2016) Reaching full density of 100Cr6 PM steel by capsule free hot isostatic pressing of high-velocity compacted material. World PM 2016 Congr. Exhib

20. Eklund A, Ahlfors M (2018) Heat treatment of PM parts by hot isostatic pressing. Met Powder Rep 73:163-169. https://doi.org/10. 1016/j.mprp.2018.01.001

21. Dlapka M, Danninger H, Gierl C, Lindqvist B (2010) Defining the pores in PM components. Met Powder Rep 65:30-33. https://doi. org/10.1016/S0026-0657(10)70093-X

22. Ahlfors M (2014) The possibilities and advantages with heat treatments in HIP. HIP14 Proc.

23. Materials and powder properties 1. In: Höganäs Handb. Sintered Components. https://www.hoganas.com/globalassets/uploadedfiles/handbooks/handbook-1-material_and_powder_properties december 2013 0674hog-interactive.pdf. Accessed 30 Jul 2018

24. Semel FJ, Lados DA (2006) Porosity analysis of PM materials by helium pycnometry. Powder Metall 49:173-182. https://doi.org/10. 1179/174329006X95347

25. Hrairi M, Chtourou H, Gakwaya A, Guillot M (2011) Modeling the powder compaction process using the finite element method and inverse optimization. Int J Adv Manuf Technol 56:631-647. https:// doi.org/10.1007/s00170-011-3211-z

26. Drucker DC, Prager W (1952) Soil mechanics and plastic analysis or limit design. Q Appl Math 10:157-165

27. Gurson AL (1977) Continuum theory of ductile rupture by void nucleation and growth: part I-yield criteria and flow rules for porous ductile media. J Eng Mater Technol 99:2-15. https://doi. org/10.1115/1.3443401

28. Wagle GS (2006) Die compaction simulation: simplifying the application of a complex constitutive model using numerical and physical experiments

29. Khodaee A, Melander A (2017) Evaluation of effects of geometrical parameters on density distribution in compaction of PM gears. AIP Conf Proc. https://doi.org/10.1063/1.5008051

30. Slimane A, Bouchouicha B, Benguediab M, Slimane S-A (2015) Parametric study of the ductile damage by the Gurson-TvergaardNeedleman model of structures in carbon steel A48-AP. J Mater Res Technol 4:217-223. https://doi.org/10.1016/j.jmrt.2014.12.011

31. Bourih A, Kaddouri W, Kanit T, Madani S, Imad A (2018) Effective yield surface of porous media with random overlapping identical spherical voids. J Mater Res Technol 7:103-117https:// doi.org/10.1016/j.jmrt.2017.01.002

32. Rutz HG, Hanejko FG (1994) High density processing of high performance ferrous materials. Adv Powder Metall Part Mater 5: 117

33. Hanejko F (2010) High density via single pressing/single sintering. Fenmo Yejin Jishu/Powder Metall Technol 28:73-76 